\title{
Correction to: Quality-Based Thermokinetic Optimization of Ready-to-Eat Whole EdibleCrab (Cancer pagurus) Pasteurisation Treatments
}

\author{
S. Condón-Abanto ${ }^{1,2} \cdot$ J. Raso $^{2} \cdot$ C. Arroyo ${ }^{1} \cdot$ J. Lyng $^{1} \cdot$ Ignacio Álvarez $^{2}$ (I)
}

Published online: 22 January 2019

(C) Springer Science+Business Media, LLC, part of Springer Nature 2019

\section{Correction to: Food Bioprocess Technol}

https://doi.org/10.1007/s11947-018-2222-2

The Figures and captions/legends at the original version of this article are displaced. With this, the corrected images are hereby published.

The original article has been corrected.

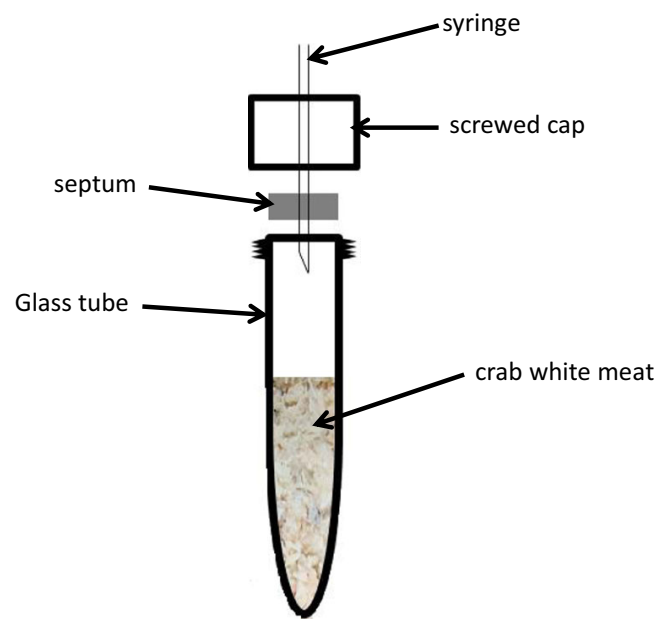

Fig. 1 The tubes used to study the colour degradation kinetics of crab white meat

The online version of the original article can be found at https://doi.org/ $10.1007 / \mathrm{s} 11947-018-2222-2$

Ignacio Álvarez

ialvalan@unizar.es

1 UCD Institute of Food and Health, University College Dublin, Belfield, Dublin 4, Ireland

2 Departamento de Producción Animal y Ciencia de los Alimentos. Tecnología de los Alimentos, Facultad de Veterinaria, Instituto Agroalimentario de Aragón-IA2 - (Universidad de Zaragoza-CITA), Zaragoza, Spain
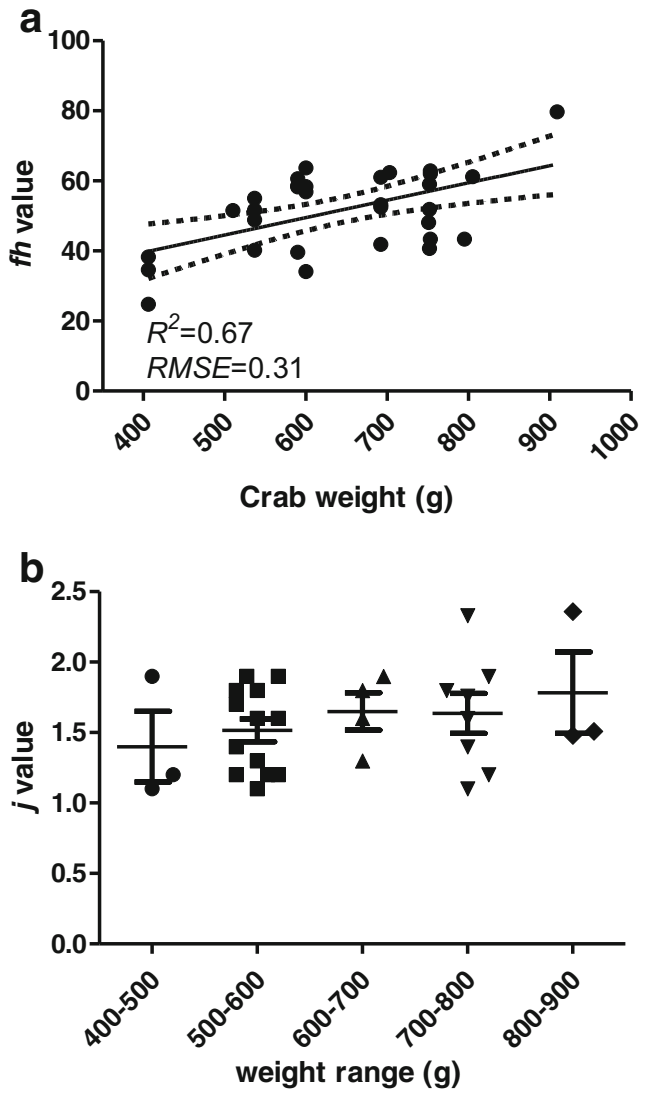

Fig. 2 Effect of crab weight on the heat penetration parameters $\mathbf{a}$ fh and $\mathbf{b}$ $j$, estimated from the fitting of Ball and Olson equation to the thermal profiles obtained in the crab cold-spot. Fig. 2a also shows the regression line (block line) as well as the $95 \%$ confidence intervals (dotted lines) 


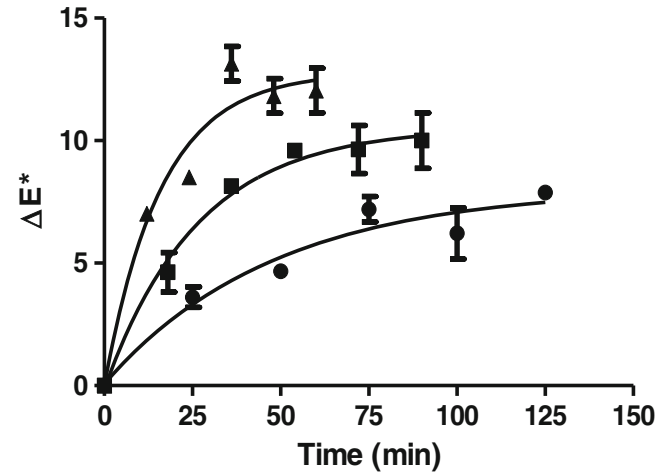

Fig. 3 Effect of the processing time on the evolution of $\Delta E^{*}$ of crab white meat at $95{ }^{\circ} \mathrm{C}$ (black circle), $105^{\circ} \mathrm{C}$ (black square) and $115^{\circ} \mathrm{C}$ (black triangle). Figure also shows the data fitting lines to Eq. 10C. Error bars represent the standard deviation of three replicates
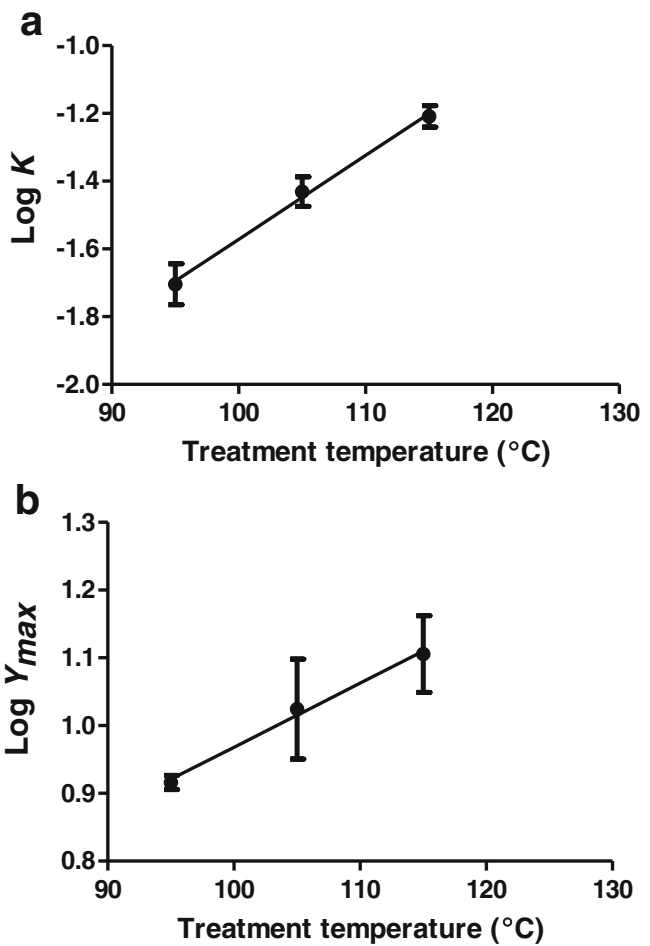

Fig. 4 Effect of the treatment temperature on the colour change rate a $(k)$ and $\mathbf{b}$ maximum colour change developed $\left(Y_{\max }\right)$ on crab white meat. Error bars show the standard deviation of three replicates

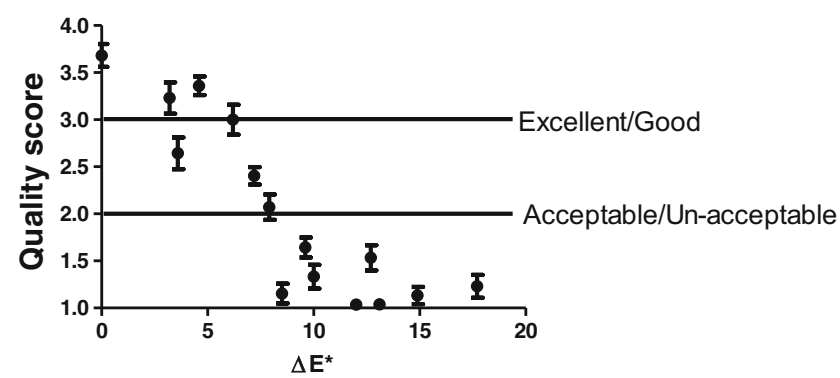

Fig. 5 Quality score associated with crab whitemeat colour change based on the Irish crab producers. Number 4 indicates the maximum quality and 1 the lowest

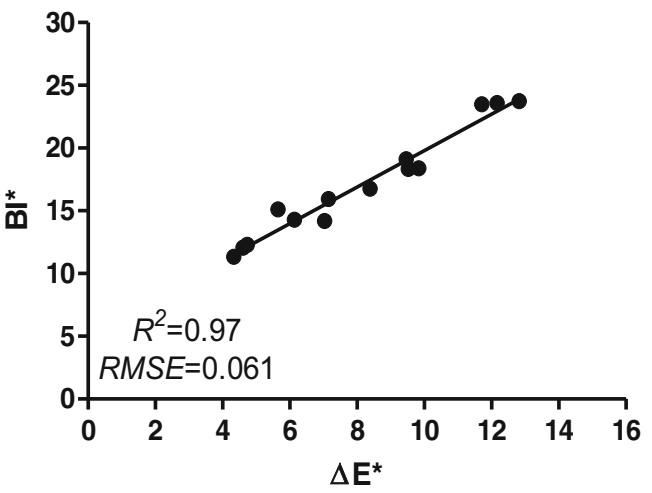

Fig. 6 Correlation between the Browning index $\left(\mathrm{BI}^{*}\right)$ and total colour change $\left(\Delta E^{*}\right)$ after different thermal treatments 


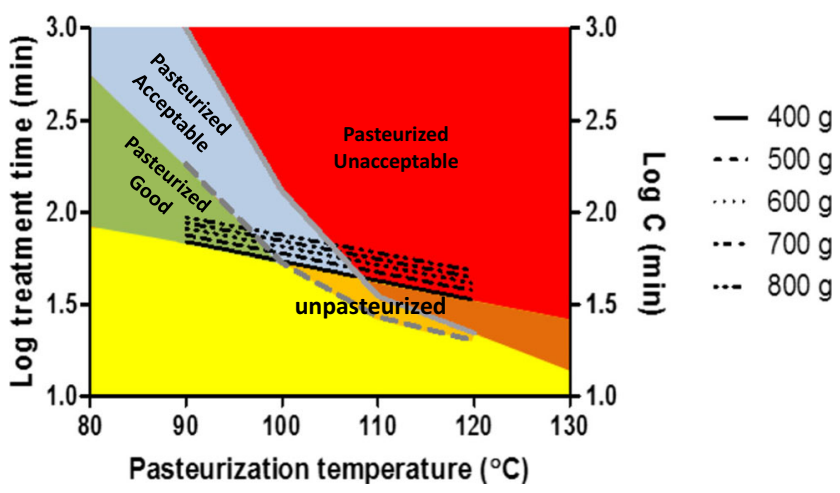

Fig. 7 Theoretical optimisation graph for the pasteurisation process of ready-to-eat whole edible crab based on Eqs. 12 and 13. Grey lines represent the quality boundaries between 'good' and 'acceptable' (dashed line) and between 'acceptable' and 'non-acceptable' (block line). Black lines represents the minimum processing conditions (time/temperature) required for crabs of different weights (from bottom to top 400, 500, 600, 700 and $800 \mathrm{~g}$ ) to achieve an adequate $F$ value based on the inactivation of $C$. botulinum type $\mathrm{E}\left(F_{90^{\circ} \mathrm{C}} 0^{\circ} \mathrm{C}=10 \mathrm{~min}\right)$
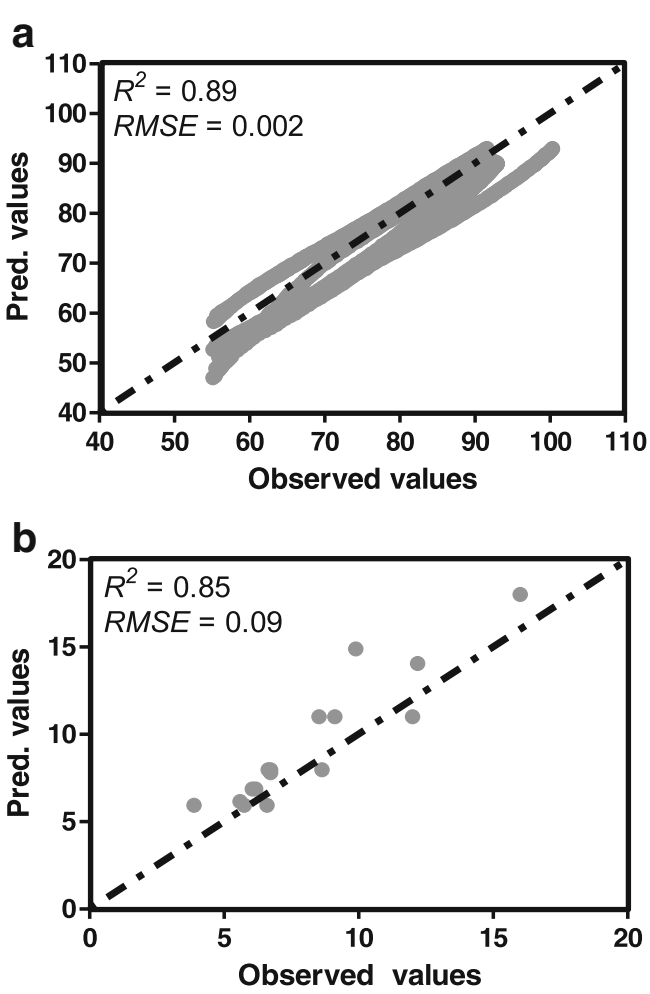

Fig. 8 Observed versus predicted values for the a thermal profiles and $\mathbf{b}$ white meat colour degradations of crabs of different weights that were pasteurised under the conditions defined in Fig. 7

Publisher's Note Springer Nature remains neutral with regard to jurisdictional claims in published maps and institutional affiliations. 